\title{
Exercise electrocardiogram testing in two brothers with different outcome - a case study exercise testing in master cyclists
}

This article was published in the following Dove Press journal:

International Journal of General Medicine

14 June 2013

Number of times this article has been viewed

\author{
Christoph Alexander Rüst ${ }^{1}$ \\ Beat Knechtle ${ }^{1,2}$ \\ Thomas Rosemann' \\ 'Institute of General Practice and \\ Health Services Research, University \\ of Zurich, Zurich, Switzerland; \\ ${ }^{2}$ Gesundheitszentrum St Gallen, \\ St Gallen, Switzerland
}

\begin{abstract}
The cases of two brothers training and competing as master cyclists and both preparing for a cycling tour are presented. The older brother aged 66 years went first to the primary care physician and presented with an asymptomatic depression in the exercise stress test of the ST segment in V5 and V6 during recovery after complete exhaustion. Coronary angiography revealed a multi vessel coronary artery disease and he underwent bypass surgery. One year later, he successfully completed his planned cycling tour of $\sim 600 \mathrm{~km}$ in seven stages and covering $\sim 12,000 \mathrm{~m}$ of total ascent. The younger brother aged 59 years went a few months later to the primary care physician and also performed asymptomatic exercise stress testing without changes in the ST segments. Unfortunately, 2 months later he suffered a cardiac arrest during his cycling tour and survived following immediate successful cardiopulmonary resuscitation on the road by his cycling colleagues. Immediate invasive coronary arteriography showed a complete stenosis of the trunk of arteria coronaria sinistra (left coronary artery), a $40 \%-50 \%$ stenosis of ramus circumflexus, and a $20 \%$ stenosis of arteria coronaria dextra (right coronary artery). The left coronary artery was dilated and he continued cycling 2 months later. In both brothers, familial hypercholesterolemia was the main cardiovascular risk factor for the multi vessel coronary artery disease. A negative exercise electrocardiogram in siblings with an increased risk for coronary artery disease seemed not to exclude an advanced multi vessel coronary artery disease. In master athletes with asymptomatic exercise electrocardiogram but a positive family history, further examinations should be performed in order to detect relevant stenosis in coronary arteries.
\end{abstract}

Keywords: cyclist, exercise stress test, electrocardiogram, coronary artery, hypercholesterolemia

\section{Introduction}

The exercise electrocardiogram (ECG) is widely considered the best available test for screening asymptomatic adults without known cardiovascular disease prior to initiating a vigorous exercise program due to its prognostic value, widespread availability, and low cost. ${ }^{1}$ Generally, the exercise ECG is used as a non-invasive method to evaluate coronary artery disease. ${ }^{2}$ It has been reported that the exercise ECG has value in diagnosing coronary artery disease and predicting its severity. ${ }^{3}$ The diagnostic accuracy of an exercise ECG varies depending on the age, the gender, and the clinical characteristics of the patient. ${ }^{4}$ We report the case of two brothers without known cardiovascular disease training and preparing as master cyclists defined as athletes who exceeded the age requisite for success in elite competition; ie, typically $35-40$ years ${ }^{5,6}$ for an event with a different outcome after exercise stress testing.
Correspondence: Beat Knechtle Facharzt FMH für Allgemeinmedizin, Gesundheitszentrum St Gallen, Vadianstrasse 26, 900 I St Gallen, Switzerland

Tel +4I 07| 2268282

Fax +4I 07| 2268272

Email beat.knechtle@hispeed.ch 


\section{Case presentation}

In June 2011, the 66 year old brother A went for a checkup prior to a planned cycling tour from Geneva (Switzerland) over the Alps to Nice (France) at the Mediterranean coast. He was healthy, had no medical problems, and trained frequently during his work life while he regularly competed in master races. During the year, he completed on average $\sim 12,000$ cycling kilometers mainly in road cycling. After his retirement, he intensified his training to prepare for the planned cycling tour and went for a routine check before starting the tour. The primary care physician performed an exercise ECG after a physical examination and some basic laboratory measurements. The physical examination of the lean master athlete with $1.76 \mathrm{~m}$ body height and $61 \mathrm{~kg}$ body mass (body mass index of $19.7 \mathrm{~kg} / \mathrm{m}^{2}$ ) showed no abnormalities. The laboratory results are presented in Table 1 and the ECG at rest is shown in Figure 1. In the ECG at rest, high T waves in the precordial leads impress. In the exercise ECG (Figure 2), he achieved 197 Watt at maximum load, equal to $146 \%$ of his target. Blood pressure was $120 / 60 \mathrm{mmHg}$ at rest and achieved a maximum of $180 / 80 \mathrm{mmHg}$ at maximum exertion. The ST segment decreased $0.9 \mathrm{~mm}$ in V5 and $1.0 \mathrm{~mm}$ in V6 during the recovery phase (4 minutes) without symptoms. The primary care physician decided to send him for invasive coronary angiography. This examination showed a $50 \%-70 \%$ stenosis of ramus interventricularis anterior (RIVA; left anterior

Table I Laboratory results of the two brothers at the time of the checkup

\begin{tabular}{|c|c|c|c|}
\hline Parameter & Reference value & Brother A & Brother B \\
\hline Hemoglobin & $13.7-17.5 \mathrm{~g} / \mathrm{dL}$ & 14.2 & 15.2 \\
\hline Hematocrit & $40.1 \%-51.0 \%$ & 42.7 & 47.3 \\
\hline Erythrocytes & 4.6-6.1 T/L & 4.6 & 5.2 \\
\hline Leucocytes & 4.2-9.1 G/L & 5.0 & 7.0 \\
\hline Thrombocytes & $140-400 \mathrm{G} / \mathrm{L}$ & 341 & 313 \\
\hline Blood sedimentation & $<\mathrm{I} 2 \mathrm{~mm} / \mathrm{h}$ & 6 & 12 \\
\hline GOT & $<40 \mathrm{U} / \mathrm{L}$ & 18 & 15 \\
\hline GPT & $<40 \mathrm{U} / \mathrm{L}$ & 15 & 16 \\
\hline Glucose & $3.5-6.1 \mathrm{mmol} / \mathrm{L}$ & 5.4 & $7.5^{*}$ \\
\hline Creatinine & $62-106 \mu \mathrm{mol} / \mathrm{L}$ & 76 & 104 \\
\hline Cholesterol & $<5 \mathrm{mmol} / \mathrm{L}$ & 8. $1^{*}$ & $7.3 *$ \\
\hline HDL-cholesterol & $0.9-1.6 \mathrm{mmol} / \mathrm{L}$ & $2.8^{*}$ & $2.0 *$ \\
\hline LDL-cholesterol & $<3 \mathrm{mmol} / \mathrm{L}$ & $4.9 *$ & $4.8 *$ \\
\hline Triglycerides & $0.6-1.7 \mathrm{mmol} / \mathrm{L}$ & 0.8 & 1.0 \\
\hline Vitamin D & $>20 \mu \mathrm{g} / \mathrm{L}$ & 23.4 & $19.3 *$ \\
\hline TSH & $0.3-5.5 \mathrm{mU} / \mathrm{L}$ & 2.1 & $19.2 *$ \\
\hline PSA & $<4 \mu \mathrm{g} / \mathrm{L}$ & 0.8 & 1.6 \\
\hline
\end{tabular}

Note: *Out of range, blood samples for brother B were not taken in an absolute fasting state.

Abbreviations: GOT, glutamic oxaloacetic transaminase; GPT, glutamic pyruvate transaminase; HDL, high-density lipoprotein; LDL, low-density lipoprotein; TSH, thyroid stimulating hormone; PSA, prostate-specific antigen. descending, LAD), a 95\% stenosis of arteria coronaria dextra (right coronary artery; RCA) and a 95\% stenosis of ramus posterolateralis of the RCA. Due to these multiple stenoses, the cardiologist recommended cancelling the planned cycling tour and sent the patient to coronary artery bypass surgery. The heart surgeon performed a myocardial revascularization with arteria mammaria interna dextra on ramus posterolateralis dexter and ramus interventricularis posterior, and arteria mammaria interna sinistra on ramus diagonalis and ramus interventricularis anterior. The patient recovered well during a stationary rehabilitation and completed his planned cycling tour successfully in the summer of 2012.

In March 2012, 59-year old brother B went to the same primary care physician also prior to a planned cycling tour in the Alps. He was also training frequently for mountain bike cycling and had neither cardiac symptoms nor any other medical problems. During the year, he completed on average $\sim 9,000$ cycling kilometers in both road and mountain bike cycling. The physical examination of the master athlete with $1.72 \mathrm{~m}$ body height and $69 \mathrm{~kg}$ body mass (body mass index of $23.3 \mathrm{~kg} / \mathrm{m}^{2}$ ) showed no abnormalities. The laboratory results are presented in Table 1 and the ECG at rest is shown in Figure 3. In the exercise ECG (Figure 4), he achieved 229 Watt, equal to $151 \%$ of his target. Blood pressure was $120 / 80 \mathrm{mmHg}$ at rest and achieved a maximum of 220/90 $\mathrm{mmHg}$ at maximum exertion. The ST segment showed no changes at both maximum exertion and in the recovery phase. Blood pressure returned to $140 / 80 \mathrm{mmHg}$ by the end of the test. Due to the high cholesterol and the increased thyroid stimulating hormone, the primary care physician decided to start with a lipid-lowering drug ( $40 \mathrm{mg}$ of simvastatin) and $0.05 \mathrm{mg}$ levothyroxine due to the latent hypothyroidism. The patient prepared for this planned cycling tour in the Alps starting May 17, 2012. The first day in a steep ascent in a mountain pass, he suffered an acute heart attack with cardiac arrest. His colleagues performed a successful cardiopulmonary resuscitation on the road and he was transferred by helicopter to the nearest hospital. The ECG by the rescue team showed ventricular fibrillation. Immediate invasive coronary arteriography showed a complete stenosis of arteria coronaria sinistra (LCA), a $40 \%-50 \%$ stenosis of ramus circumflexus, and a $20 \%$ stenosis of arteria coronaria dextra (RCA). The LCA was dilated. Due to the fall off the bike, he also suffered a fracture of his first vertebra of the lumbar spine (L1). The ejection fraction of the left ventricle was $55 \%$ upon discharge from hospital. He was sent to cardiac rehabilitation where he fully recovered. Two months after the cardiac arrest, he was again training and cycling. 


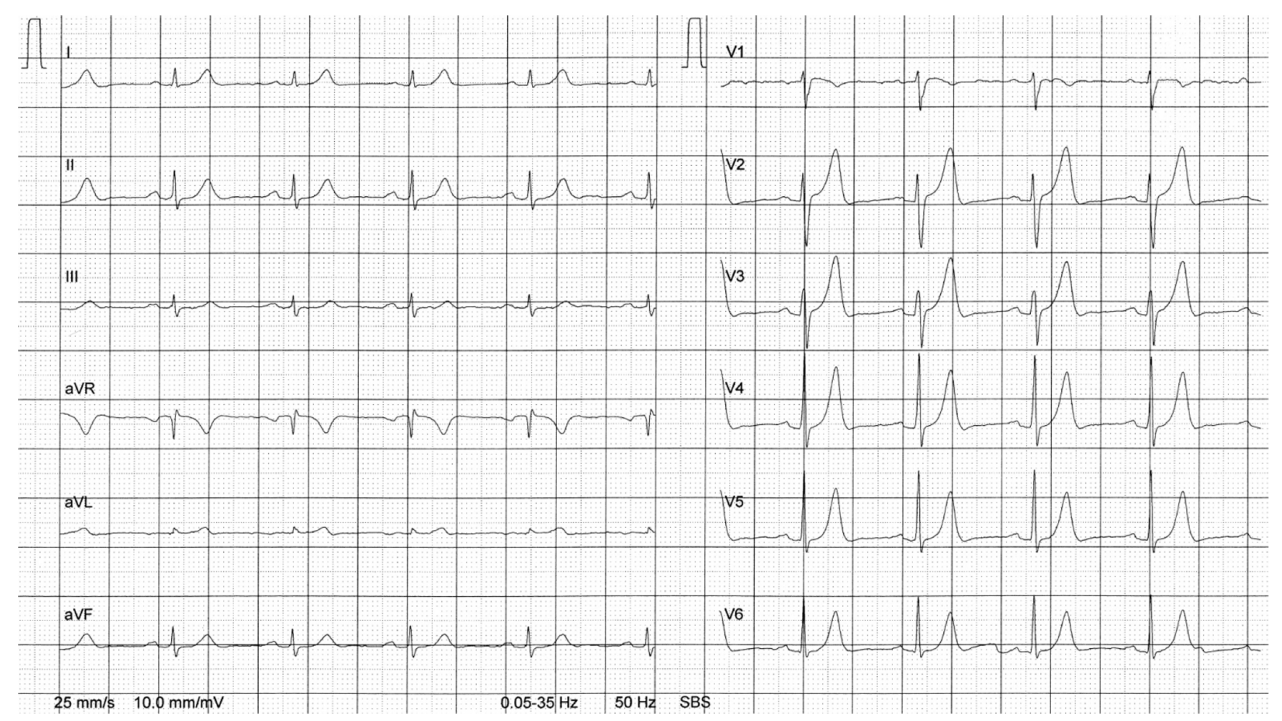

Figure I ECG at rest from brother A.

Abbreviations: aVF, augmented unipolar limb lead in which the positive electrode is on the left leg; aVL, augmented unipolar limb lead in which the positive electrode is on the left arm; aVR, augmented unipolar limb lead in which the positive electrode is on the right arm; ECG, electrocardiogram; SBS, SCHILLER Baseline-Stabilizer.

In the family history of the two brothers, the father died at the age of 70 years due to a heart attack. The mother died at the age of 90 years with no history of coronary heart disease. In autumn 2012, the third brother of the two brothers described herein was sent for an exercise ECG in order to assess the risk of coronary artery disease. This brother also achieved more than the target in the exercise stress test and the exercise ECG revealed no ST segment depression. Due to hypercholesterolemia, he was treated since 2008 with $40 \mathrm{mg}$ of atorvastatin. He agreed to invasive coronary arteriography due to his high risk of heart attack. This examination showed advanced atherosclerosis in all of his coronary arteries.

\section{Discussion}

In brother A, the ST segment depression appeared in the recovery phase of the exercise ECG, but not during exercise. Lanza et al investigated the diagnostic and prognostic value of an ST segment depression limited to the recovery phase of an exercise stress test and compared it to that of an ST segment depression during exercise. ${ }^{7}$ They found that the diagnostic and prognostic power of the ST segment depression limited to the recovery phase of an exercise ECG was largely similar to that of the ST segment depression induced during effort. Also, Rashid et al reported that in patients undergoing exercise ECG, ST segment depression occurring only in the recovery phase of an exercise ECG had diagnostic value largely comparable with that of ST segment depression induced during the exercise phase of the exercise ECG. ${ }^{8}$ The post-exercise ST segment depression without ST segment depression during exercise ECG may be associated with an abnormal response to imbalances in the cardiovascular sympathetic system in the post-exercise period rather than with myocardial ischemia. ${ }^{9}$

Both brothers suffered from a multi vessel coronary artery disease. However, only in brother A did the exercise ECG reveal an ST segment depression in the recovery phase. Sun et al found that patients with multi vessel disease had a higher positive rate in exercise ECG compared to those with single vessel disease. ${ }^{10} \mathrm{Wu}$ et al compared the results of exercise ECG and coronary angiography in 461 patients. ${ }^{11}$ They showed that positive results of exercise ECG with downslope or horizontal depression of the ST segment more than $0.1 \mathrm{mV}$ during or after exercise may predict coronary artery disease, the sensitivity of which was $74.5 \%$ (322 cases) and the specificity as $84.2 \%$ (139 cases). With the use of ST depression more than $0.2 \mathrm{mV}$ as the super-positive standard, the sensitivity and specificity of positive exercise ECG to predict triple vessel disease and left main coronary disease was $61.3 \%$ and $79.1 \%$, respectively. The duration of the ST segment depression had a positive correlation with the number of diseased coronary arteries. The patients with multi vessel disease and left main coronary artery disease had a higher positive rate of exercise ECG testing compared to patients with single or double vessel disease. It was concluded that exercise ECG testing had some value in diagnosing coronary artery disease and predicting its severity. Some parameters in exercise ECG were also helpful for predicting the severity of coronary artery disease.

Pigozzi et al evaluated the prevalence and clinical significance of ST segment depression during an exercise 


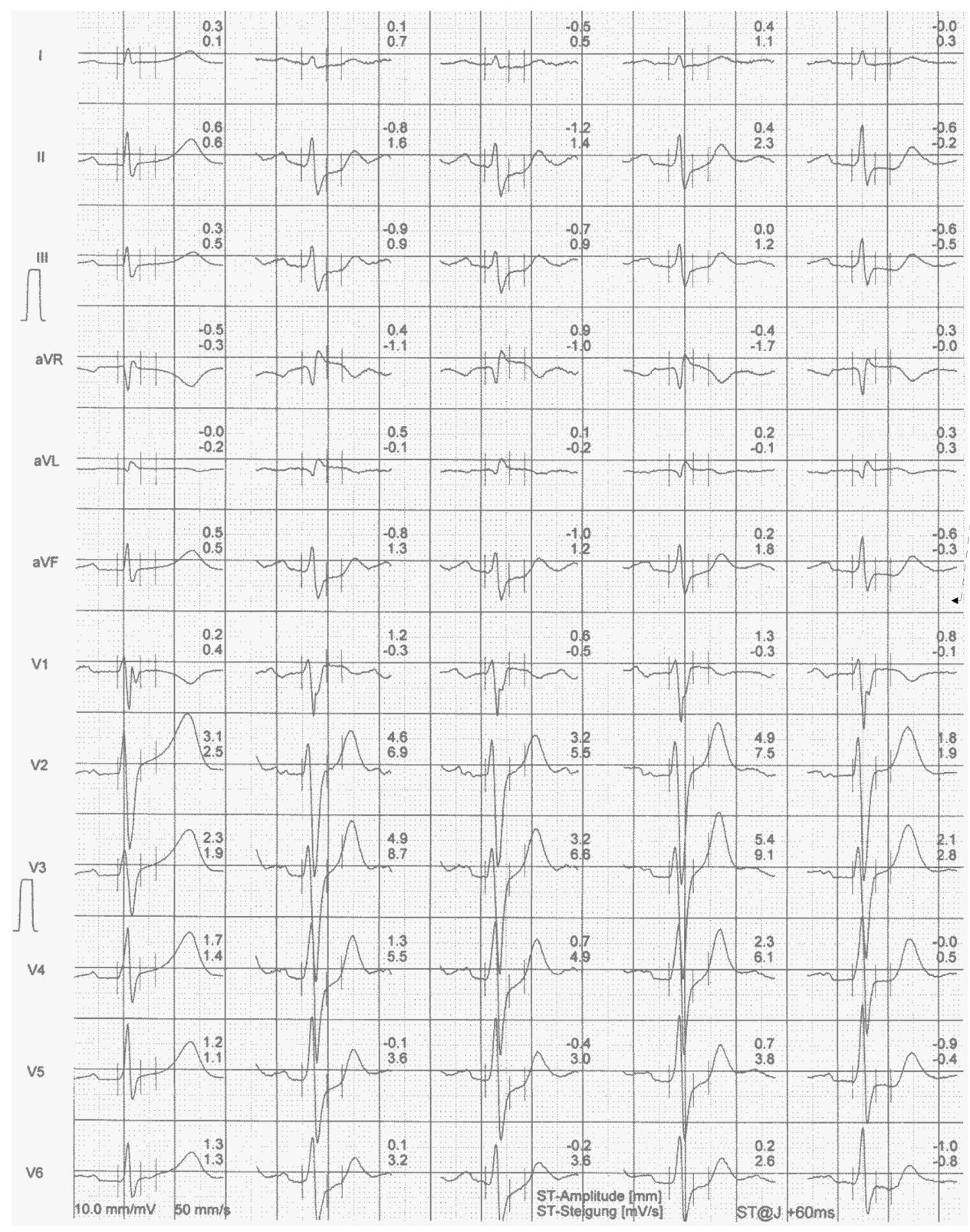

Figure 2 Exercise ECG from brother A.

Notes: First row $=$ at rest; second row $=$ last step before maximum exertion; third row = maximum exertion; fourth row $=$ after 2 minutes of recovery; fifth row $=$ after 4 minutes of recovery.

Abbreviations: aVF, augmented unipolar limb lead in which the positive electrode is on the left leg; aVL, augmented unipolar limb lead in which the positive electrode is on the left arm; aVR, augmented unipolar limb lead in which the positive electrode is on the right arm; ECG, electrocardiogram.

ECG in 113 asymptomatic apparently healthy elderly male athletes. ${ }^{12}$ A significant ST segment depression at peak exercise was detected in one athlete at the first evaluation. A further case was seen during the follow up period in a previously "negative" athlete. Both athletes were asymptomatic and single photon emission computed tomography (SPECT) and/or stress echocardiography (ECHO) were negative for myocardial ischemia. They concluded that athletes with exercise induced ST segment depression with no associated symptoms and/or complex ventricular arrhythmias and no adverse findings at second level cardiologic testing should be considered free from coronary disease and safe to continue athletic training.

For master athletes, Freeman et al recommend screening exercise ECG in asymptomatic men with diabetes and asymptomatic men over the age of 45 years with two or more cardiovascular risk factors prior to initiating a vigorous exercise program. ${ }^{1}$ In the present case, it was pure luck that the coronary artery disease was discovered. The primary care physician performed the exercise stress test in the older brother only to show the wife that the master athlete would be able to complete the planned bike ride. 


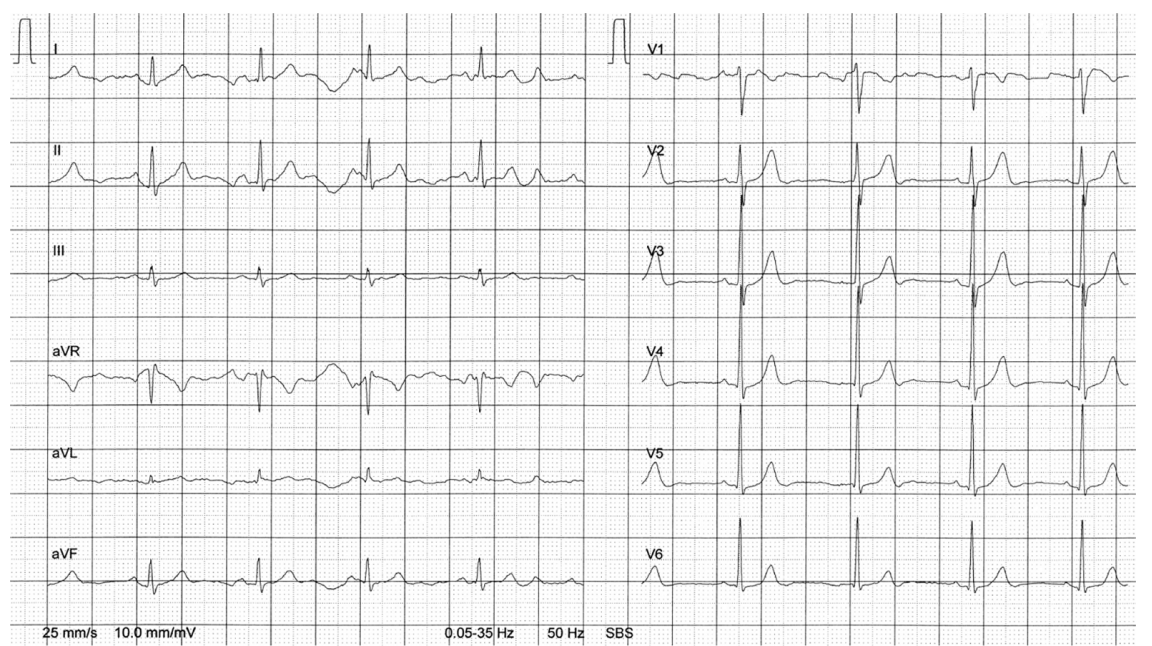

Figure $3 \mathrm{ECG}$ at rest from brother $\mathrm{B}$.

Abbreviations: aVF, augmented unipolar limb lead in which the positive electrode is on the left leg; aVL, augmented unipolar limb lead in which the positive electrode is on the left arm; aVR, augmented unipolar limb lead in which the positive electrode is on the right arm; ECG, electrocardiogram; SBS, SCHILLER Baseline-Stabilizer.

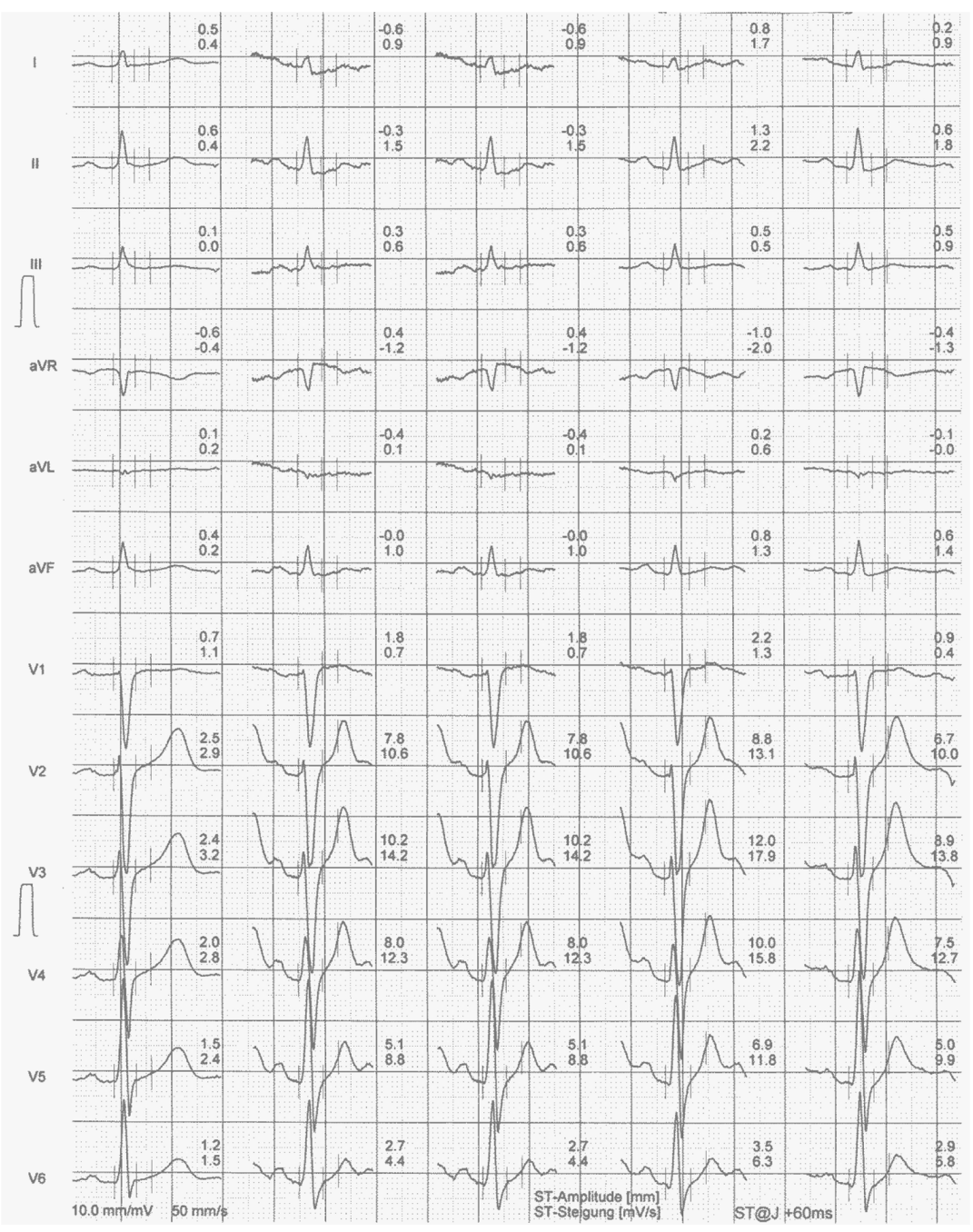

Figure 4 Exercise ECG from brother $B$.

Notes: First row $=$ at rest; second row = last step before maximum exertion; third row = maximum exertion; fourth row = after 2 minutes of recovery; fifth row = after 4 minutes of recovery.

Abbreviations: aVF, augmented unipolar limb lead in which the positive electrode is on the left leg; aVL, augmented unipolar limb lead in which the positive electrode is on the left arm; aVR, augmented unipolar limb lead in which the positive electrode is on the right arm; ECG, electrocardiogram. 
In these two brothers, the father died at the age of 70 years due to a myocardial infarction. Leander et al showed that family history of coronary heart disease is not only a strong risk factor for myocardial infarction in both sexes, but that its effect was synergistic with other cardiovascular risk factors, as well. ${ }^{13}$ Siblings of patients with coronary artery disease would benefit from investigating and treating cardiovascular risk factors. Hengstenberg et al analyzed the risk profile as well as the current utilization of preventive strategies in asymptomatic siblings of patients with myocardial infarction. ${ }^{14}$ Most asymptomatic individuals with positive fraternal family history had more than one modifiable risk factor. Rissanen investigated the occurrence of different clinical manifestations of coronary heart disease among the parents and siblings of 309 men with coronary heart disease, including 103 men with fatal and 100 with nonfatal myocardial infarction, and 106 men with angina pectoris and among the relatives of 106 reference men. ${ }^{15}$ Coronary heart disease was equally common among relatives of all subjects. It was four times as common in case brothers and twice as common in case sisters as in the respective reference siblings. Cardiac deaths were most common in the siblings of men with fatal myocardial infarction, and uncomplicated angina in the men with angina pectoris. The familial resemblance in the clinical manifestations of coronary heart disease suggested familial influence in the mechanisms determining the clinical expression of the disease.

Most of the strong familial component in coronary heart disease of early onset thus appears to be mediated by familial hyperlipidemia and hypertension. ${ }^{16}$ The risk of premature coronary heart disease in persons at highest risk could be largely eliminated if information about family history were used to identify such persons at an early stage and if they were treated properly for their correctable risk factors. ${ }^{16}$ Both brothers showed hypercholesterolemia upon their first visit to the primary care physician. The high cholesterol values as a high risk for heart diseases can explain the result of both brothers, instead of the positive family history. The younger brother also had a subclinical hypothyroidism with increased thyroid stimulating hormone levels. High thyroid stimulating hormone levels are associated with a non-favorable lipid profile $^{17}$ and with an increased risk for all-cause and cardiovascular mortality in adults. ${ }^{18}$ Most of the heart attacks, however, happen not with non-significant stenosis but with mild to moderated disease with plaque rupture, causing STelevation myocardial infarction. ${ }^{19}$ Overall, the patient would have needed better risk factor management rather than a further cardiac evaluation as he was asymptomatic.
Apart from hypercholesterolemia, diabetes mellitus type II is also an important risk factor for coronary artery disease. ${ }^{20,21}$ Brother B had elevated blood glucose upon the check-up. However, the blood samples were not drawn in an absolute fasting state and subsequent determination of blood glucose showed normal values. Further, lipoprotein(a) is an established risk marker of coronary artery disease, which is independent from other risk factors. ${ }^{22,23}$ Unfortunately, this marker was not determined in these two brothers.

In brother $\mathrm{A}$, impressive $\mathrm{T}$ waves were recorded in the precordial leads prior to the exercise ECG. A potential reason for high $\mathrm{T}$ waves in precordial leads could be hyperkalaemia. However, the electrolytes potassium $(3.9 \mathrm{mmol} / \mathrm{L})$, sodium $(138 \mathrm{mmol} / \mathrm{L})$, and creatinine $(82 \mu \mathrm{mol} / \mathrm{L})$ were in the normal range during the hospital stay for the coronary angiography.

A negative exercise ECG in siblings with an increased risk for coronary artery disease seemed not to exclude advanced multi vessel coronary artery disease. In master athletes with asymptomatic exercise ECG but a positive family history, further examinations should be performed in order to detect relevant stenosis in coronary arteries. Technological advances in recent decades have produced several methods of non-invasive cardiac imaging for the diagnosis of coronary artery disease, such as stress ECHO, myocardial perfusion radionuclide imaging, cardiac computed tomography, and cardiac magnetic resonance imaging. There is always a balance of cost and benefit for further examinations. The choice of an appropriate technique depends on the availability of the method, the patient's clinical characteristics, and other factors, such as costs, risks, radiation, and potential contrast agent toxicity. ${ }^{24,25}$ Stress ECHO and myocardial perfusion scintigraphy are widely available and most extensively validated. Stress ECHO is a non-invasive technology that images the heart using ultrasound and is a useful imaging modality for the diagnosis of coronary artery disease in suspected patients. ${ }^{26}$ Myocardial perfusion scintigraphy is a widely used nuclear, non-invasive image acquisition technique for investigating ischemic heart disease. ${ }^{27}$

\section{Disclosure}

The authors report no conflicts of interest in this work.

\section{References}

1. Freeman J, Froelicher V, Ashley E. The ageing athlete: screening prior to vigorous exertion in asymptomatic adults without known cardiovascular disease. Br J Sports Med. 2009;43(9):696-701.

2. Sharma K, Kohli P, Gulati M. An update on exercise stress testing. Curr Probl Cardiol. 2012;37(5):177-202. 
3. Ovrehus KA, Jensen JK, Mickley HF, et al. Comparison of usefulness of exercise testing versus coronary computed tomographic angiography for evaluation of patients suspected of having coronary artery disease. Am J Cardiol. 2010;105(6):773-779.

4. Banerjee A, Newman DR, Van den Bruel A, Heneghan C. Diagnostic accuracy of exercise stress testing for coronary artery disease: a systematic review and meta-analysis of prospective studies. Int J Clin Pract. 2012;66(5):477-492.

5. Ransdell LB, Vener J, Huberty J. Master athletes: an analysis of running, swimming and cycling performance by age and gender. J Exerc Sci Fit. 2009;7:61-73.

6. Reaburn P, Dascombe B. Endurance performance in masters athletes. Eur Rev Aging Phys Act. 2008;5:31-42.

7. Lanza GA, Mustilli M, Sestito A, Infusino F, Sgueglia GA, Crea F. Diagnostic and prognostic value of ST segment depression limited to the recovery phase of exercise stress test. Heart. 2004;90(12): 1417-1421.

8. Rashid MA, Mallick NH, Alam SN, Noeman A, Ehsan A, Hussain A. Usefulness of ST segment depression limited to the recovery phase of exercise stress test. J Coll Physicians Surg Pak. 2009;19(1):3-6.

9. Shinmura K, Suganuma Y, Hasegawa H, et al. Clinical significance and mechanism of ST-segment changes during the post-exercise recovery period in male patients with coronary artery disease. $J$ Cardiol. 1996;27(5):231-239. Japanese.

10. Sun JL, Han R, Guo JH, Li XY, Ma XL, Wang CY. The diagnostic value of treadmill exercise test parameters for coronary artery disease. Cell Biochem Biophys. 2013;65(1):69-76.

11. Wu L, Zhang J, Shao G. A comparative study on coronary angiography and exercise ECG testing. Zhonghua Nei Ke Za Zhi. 1996;35(2): 107-109. Chinese.

12. Pigozzi F, Spataro A, Alabiso A, et al. Role of exercise stress test in master athletes. Br J Sports Med. 2005;39(8):527-531.

13. Leander K, Hallqvist J, Reuterwall C, Ahlbom A, de Faire U. Family history of coronary heart disease, a strong risk factor for myocardial infarction interacting with other cardiovascular risk factors: results from the Stockholm Heart Epidemiology Program (SHEEP). Epidemiology. 2001;12(2):215-221.

14. Hengstenberg C, Holmer SR, Mayer B, et al. Siblings of myocardial infarction patients are overlooked in primary prevention of cardiovascular disease. Eur Heart J. 2001;22(11):926-933.

15. Rissanen AM. Familial occurrence of coronary heart disease according to clinical manifestation. Acta Med Scand. 1985;218(4):355-363.

16. Rissanen AM. Familial occurrence of coronary heart disease: effect of age at diagnosis. Am J Cardiol. 1979;44(1):60-66.
17. Duntas LH, Brenta G. The effect of thyroid disorders on lipid levels and metabolism. Med Clin North Am. 2012;96(2):269-281.

18. Tseng FY, Lin WY, Lin CC, et al. Subclinical hypothyroidism is associated with increased risk for all-cause and cardiovascular mortality in adults. J Am Coll Cardiol. 2012;60(8):730-737.

19. Anderson JL, Adams CD, Antman EM, et al; 2011 Writing Group Members; ACCF/AHA Task Force Members. 2011 ACCF/AHA Focused Update Incorporated Into the ACC/AHA 2007 Guidelines for the Management of Patients With Unstable Angina/Non-ST-Elevation Myocardial Infarction: a report of the American College of Cardiology Foundation/American Heart Association Task Force on Practice Guidelines. Circulation. 2011;123(18):e426-e579.

20. Sheikh-Ali M, Raheja P, Borja-Hart N. Medical management and strategies to prevent coronary artery disease in patients with type 2 diabetes mellitus. Postgrad Med. 2013;125(1):17-33.

21. Malik S, Billimek J, Greenfield S, Sorkin DH, Ngo-Metzger Q, Kaplan SH. Patient complexity and risk factor control among multimorbid patients with type 2 diabetes: results from the R2D2C2 study. Med Care. 2013;51(2):180-185.

22. Jaeger BR, Richter Y, Nagel D, et al. Longitudinal cohort study on the effectiveness of lipid apheresis treatment to reduce high lipoprotein(a) levels and prevent major adverse coronary events. Nat Clin Pract Cardiovasc Med. 2009;6(3):229-239.

23. Jaeger BR, Labarrere CA. Genetic variants in $\mathrm{Lp}(\mathrm{a})$ lipoprotein and coronary disease. $N$ Engl J Med. 2010;362(12):1146-1147; author reply 1147 .

24. Jaarsma C, Leiner T, Bekkers SC, et al. Diagnostic performance of noninvasive myocardial perfusion imaging using single-photon emission computed tomography, cardiac magnetic resonance, and positron emission tomography imaging for the detection of obstructive coronary artery disease: a meta-analysis. J Am Coll Cardiol. 2012;59(19):1719-1728.

25. Dowsley T, Al-Mallah M, Ananthasubramaniam K, Dwivedi G, McArdle B, Chow BJ. The role of noninvasive imaging in coronary artery disease detection, prognosis, and clinical decision making. Can J Cardiol. 2013;29(3):285-296.

26. Health Quality Ontario. Stress echocardiography for the diagnosis of coronary artery disease: an evidence-based analysis. Ont Health Technol Assess Ser. 2010;10(9):1-61.

27. Health Quality Ontario. Single photon emission computed tomography for the diagnosis of coronary artery disease: an evidence-based analysis. Ont Health Technol Assess Ser. 2010;10(8):1-64.
International Journal of General Medicine

\section{Publish your work in this journal}

The International Journal of General Medicine is an international peer-reviewed open-access journal that focuses on general and internal medicine, pathogenesis, epidemiology, diagnosis, monitoring and treatment protocols. The journal is characterized by the rapid reporting of reviews, original research and clinical studies across all disease areas.

\section{Dovepress}

A key focus is the elucidation of disease processes and management protocols resulting in improved outcomes for the patient. The manuscript management system is completely online and includes a very quick and fair peer-review system. Visit http://www.dovepress.com/ testimonials.php to read real quotes from published authors. 